\title{
Employability Management of ICT Professionals
}

Dora Scholarios

University of Strathclyde, Scotland

Esther van der Schoot

University of Twente, The Netherlands

\author{
Beatrice van der Heijden \\ Maastricht School of Management, Open University of The Netherlands and Open University of Twente, \\ The Netherlands
}

\section{INTRODUCTION}

The article describes work conducted as part of the Indic@tor project funded by the European Commission (IST-2000-31070) and supported by the Netherlands Organization for Scientific Research (NWO) (Aspasia program 015.000.114). The study examines the employability of ICT professionals and its management by small- and medium-sized enterprises (SMEs) in Europe against the backdrop of the expanding but turbulent ICT sector. Employability can be defined as the extent to which employees have skills that the market and employers regard as attractive. The development of technical and professional workers is an area of high priority for governments concerned with creating an adequate supply of skilled labour and fuelling economic growth, while for SMEs, there is general concern about the supply and utilisation of ICT skills, high turnover of experienced staff, and the under supply of qualified new entrants into the profession (Cappelli, 2001; Hill \& Stewart, 1999; ITNTO/AISS, 1999).

Employability has gained in importance as the nature of employment and work patterns, particularly in knowledge-intensive industries, has changed. Discontinuous forms of employment, such as temporary contracts and increasing subcontracting, mean that employers are viewed increasingly as providers of the necessary knowledge and skills which enhance employability rather than secure employment (Arthur, Inkson \& Pringle, 1999; Cappelli, 1999).

This highlights a tension between the role that should be played by organizations and individual employees in continuously updating knowledge and skills to enhance professional development. Employers generally do not take full responsibility for eliminating perceived skill gaps in their companies either through strategies for retaining highly qualified staff or through the provision of expensive training, mentoring or other development strategies. They may be reluctant to invest in the development of skills that make their employees more marketable while employees themselves may develop expertise that is too narrow to stay employable in the long run and keep up with technological and scientific developments.

Highly qualified employees may also face declining reemployability when entering later stages of their career (Boerlijst, Munnichs \& Van der Heijden, 1998; Van der Heijden, 2002). The consideration of age-related issues in career development is relatively recent (see also, Hall, 2002) but there is growing concern about guiding individuals' professional development throughout their working life facilitating life-long learning approaches (see, for example, Kwakman et al., 2002). Given the aging and dejuvenization of the working population (i.e., the increasing proportion of older people coupled with decreasing proportions of young people in the labour force) and the tendency for older employees, working in middle and higher-level functions, to become immobile and overspecialized in narrow occupational domains, the need to ensure employability throughout the working career is apparent. Yet, the extent to which either management or employees themselves are actively engaged in furtherance of the professional career noticeably declines when the employees age. The consequences may be serious for older employees whose function becomes obsolete and who are unable to adapt to changing requirements.

\section{OBJECTIVES}

Despite the increasing importance of employability for governments, employers and employees, there has been little scientific study of how employability is acquired by individuals and how it can be developed and sustained over the life cycle of a career, especially in the relatively new ICT sector and for smaller employers with limited resources. The present study attempts to address this gap by examining employability of ICT professionals in different European countries and the management of employability by ICT SMEs. This contribution has three objectives: 
1. To examine the nature of employment in the ICT sector in seven European countries (Germany, Greece, Italy, the Netherlands, Norway, Poland, and the UK), each of which is expected to represent different employment conditions for ICT professionals.

2. To explore the perceptions of ICT SME employers in these countries with regard to the importance of employability for their organizations and their concerns in attempting to manage this quality of employees.

3. To consider the implications of the study findings for sustaining employability across Europe, particularly in terms of the expected role of SME employers and the development of professional expertise through all career stages.

\section{METHODOLOGY}

The empirical focus involves two analyses, one using secondary data sources and the other based on qualitative interviews of ICT SME managers. First, an analysis of the ICT sector in the seven countries based on crossnational and national data sources provides a summary of the key features of the ICT sector, including its contribution to economic growth, and a description of the highskilled ICT workforce (e.g., demographic characteristics, labour market supply and demand for ICT professionals, and the nature of companies employing ICT professionals). The seven countries were chosen largely on the basis of convenience sampling (based on well-established relationships between research institutes) while also aiming to represent the ICT sector in Europe. They represent five different clusters within the European Community; the Netherlands and Germany (Germanic Cluster), UK (AngloSaxon cluster), Norway (Nordic Cluster), Poland (Eastern European Cluster), Greece (Near-East Cluster), and Italy (Latin Cluster).

The second analysis involved interviews with a selected group of managing directors, CEOs or managers in ICT SMEs who were representative of the population of ICT companies identified in the sector analysis. This was intended to explore employers' understanding of occupational expertise of ICT professionals, and the extent of practice addressing employability issues (e.g., dealing with skills gaps, performance assessment, or career planning). Interviews were conducted in all seven countries from April 2002 to February 2003 and aimed for five companies in each of three SME size bands: 10-49 employees, 50-149 employees, and 150-249 employees. A common semi-structured interview protocol was used covering three themes: employability, aging and future developments and requirements. The final number of inter-
Table 1. Number of interviews conducted by SME size

\begin{tabular}{l|cccc}
\hline Country & \multicolumn{4}{|c}{ Number of employees } \\
\hline \multirow{3}{*}{ Germany } & $10-49$ & $50-149$ & $150-249$ & Total \\
Greece & 3 & 7 & 5 & 15 \\
The Netherlands & 13 & 2 & 0 & 15 \\
Norway & 10 & 2 & 3 & 15 \\
Italy & 5 & 5 & 5 & 15 \\
Poland & 10 & 3 & 2 & 15 \\
United Kingdom & 6 & 6 & 6 & 18 \\
Total & 8 & 5 & 1 & 14 \\
\hline
\end{tabular}

views conducted was 107 ; numbers by company size in each country are shown in Table 1.

All final interview transcriptions were analyzed at a national level by researchers in each country according to a common coding scheme. This was constructed on the basis of three Dutch interviews by subdividing the data into core labels (variable categories) representing each of the three interview themes, dimensions of these core labels, and loadings (Baarda, De Goede, \& Teunissen, 1995). For example, the core label employability included the dimension 'employability management'. A loading represents a group of similar statements given by respondents that are indicative of a certain dimension. Researchers at the national level were able to add additional categories to this general framework for each item. Comparable answering patterns were aggregated in the crosscultural analysis to produce an overall frequency table of responses.

\section{RESULTS}

\section{The ICT Market in the Seven Countries}

The European Information Technology Observatory's (EITO) 2003 overview of the ICT sector across Europe shows a picture of rapid growth during the 1990s and decline since 2000. Market evaluations for 2002-2003 indicated zero growth in Europe in 2002 and the prospect of limited development in 2003 (growth of $2.5 \%$ ) (EITO, 2003). However, there is expected to be a strong growth in Internet penetration and broadband connections (DSL and cable). This has led the EITO to forecast $3.1 \%$ growth in the total ICT market for Western Europe in 2004 with some segments of the market, particularly software products and carrier services, showing stronger performance (EITO Update, 2003). 
5 more pages are available in the full version of this document, which may be purchased using the "Add to Cart" button on the publisher's webpage:

www.igi-global.com/chapter/employability-management-ict-professionals/11391

\section{Related Content}

Strategic Directions in European Sustainable City Management

Nemanja Backovi, Vesna Milievi and Adam Sofronijevic (2019). Smart Cities and Smart Spaces: Concepts,

Methodologies, Tools, and Applications (pp. 1583-1604).

www.irma-international.org/chapter/strategic-directions-in-european-sustainable-city-management/211358/

Investigating E-Planning in Practice: Applying the Unified Theory of Acceptance and Use of Technology Model

Wayne Williamson and Bruno Parolin (2013). International Journal of E-Planning Research (pp. 17-29).

www.irma-international.org/article/investigating-e-planning-in-practice/95054/

E-Planning and Public Participation: Addressing or Aggravating the Challenges of Public Participation in Planning?

Mhairi Aitken (2014). International Journal of E-Planning Research (pp. 38-53).

www.irma-international.org/article/e-planning-and-public-participation/114160/

Smart City Governance: From E-Government to Smart Governance

Maria do Rosário Matos Bernardo (2019). Smart Cities and Smart Spaces: Concepts, Methodologies, Tools, and

Applications (pp. 196-232).

www.irma-international.org/chapter/smart-city-governance/211292/

Smart City, Integrated Planning, and Multilevel Governance: A Conceptual Framework for e-Planning in Europe

Lukasz Damurski (2016). International Journal of E-Planning Research (pp. 41-53).

www.irma-international.org/article/smart-city-integrated-planning-and-multilevel-governance/164424/ 